\title{
Heparin-like Entities from Marine Organisms
}

\author{
S. Colliec-Jouault ${ }^{\mathrm{a},{ }^{*}}$, C. Bavington ${ }^{\mathrm{b}}$, C. Delbarre-Ladrat ${ }^{\mathrm{a}}$ \\ a Laboratoire de Biotechnologie et Molécules Marines, Ifremer, Rue de l'lle d'Yeu, 21105, 44311, Nantes Cedex \\ 3, France \\ b Dunstfaffnage Marine Laboratory, Glycomar Ltd, European Centre for Marine Biotechnology, Dunbeg, Oban, \\ Argyll, PA37 1QA, UK \\ *: Corresponding author : S. Colliec-Jouault, email address : Sylvia.Colliec.Jouault@ifremer.fr
}

\begin{abstract}
:
Polysaccharides are ubiquitous in animals and plant cells where they play a significant role in a number of physiological situations e.g. hydration, mechanical properties of cell walls and ionic regulation. This review concentrates on heparin-like entities from marine procaryotes and eukaryotes. Carbohydrates from marine prokaryotes offer a significant structural chemodiversity with novel material and biological properties. Cyanobacteria are Gram-negative photosynthetic prokaryotes considered as a rich source of novel molecules, and marine bacteria are a rich source of polysaccharides with novel structures, which may be a good starting point from which to synthesise heparinoid molecules. For example, some sulphated polysaccharides have been isolated from gamma-proteobacteria such as Alteromonas and Pseudoalteromonas sp. In contrast to marine bacteria, all marine algae contain sulphated wall polysaccharides, whereas such polymers are not found in terrestrial plants. In their native form, or after chemical modifications, a range of polysaccharides isolated from marine organisms have been described that have anticoagulant, antithrombotic, anti-tumour, anti-proliferative, anti-viral or anti-inflammatory activities.
\end{abstract}

In spite of the enormous potential of sulphated oligosaccharides from marine sources, their technical and pharmaceutical usage is still limited because of the high complexity of these molecules. Thus, the production of tailor-made oligo- and polysaccharidic structures by biocatalysis is also a growing field of interest in biotechnology.

Keywords: Anticoagulant activity; Anti-inflammatory activity; Anti-thrombotic activity; Chemical modification ; Cyanobacteria ; Derivatives ; Exopolysaccharides ; Heparinoids ; Heparin-like entities ; Marine algae ; Marine bacteria ; Marine fungi ; Structure ; Sulphated polysaccharides 


\section{Heparin-like Entities from Cyanobacteria}

Cyanobacteria (blue-green algae) are Gram-negative prokaryotic organisms highly structurally organized and morphologically differentiated. They are among the most primitive forms of life on earth. During the two billion years they have flourished on the earth, they have virtually not changed both morphologically and physiologically [1].

Cyanobacteria include edible and toxic species. Nostoc, Spirulina and Aphanizomenon are the main edible cyanobacteria. Many of the commercial important natural products that are derived from cyanobacteria are complex organic compounds that possess unique structures and stereochemistry. In 2009, Rastogi and Sinha have reviewed the innovative pharmacologically active compounds derived from cyanobacteria showing biological activities as antibiotics, immunosuppressant, anticancer, antiviral, anti-inflammatory and protease inhibitors [2]. Cyanobacteria produce a wide variety of toxins and other bioactive compounds, which include lipopeptides, amino acids, fatty acids, macrolides and amides [3].

Despite the importance of marine cyanobacteria as a source of bioactive secondary metabolites [4], very few marine cyanobacteria have been studied for the polysaccharide they produce. Polysaccharides are mainly present as capsules and/or slimes in cyanobacteria. A small portion of them are usually released as water-soluble polymer (RPS) [5]. They are complex anionic heteropolysaccharides usually containing uronic acids. Some of them are also sulphated $[5,6]$. 


\subsection{Spirulina}

Spirulan, existing as a ionic form (calcium or sodium), is a sulphated polysaccharide isolated from Arthrospira platensis (formely Spirulina platensis) and consisting of two types of disaccharide repeating units, $[\rightarrow 3)-\alpha-\mathrm{L}-\mathrm{Rha}(1 \rightarrow 2)-\alpha-\mathrm{L}-\mathrm{Aco}-(1 \rightarrow]$ where Aco (acofriose) is 3 - $O$-methyl-Rha with sulphate groups and $O$-hexuronosyl-rhamnose. It also contains trace amounts of xylose, glucuronic acid and galacturonic acid [7]. Its molecular weight is about 200000 and bears from 5 to $20 \%$ sulphate depending on the source $[8,9]$.

Spirulan and spirulan-like substances have been widely studied for anti-viral activity without any cytotoxic effects $[10,11]$.

The ultrafiltrated spirulan is endowed with an anticoagulant activity, only 5-times lower than standard unfractionated heparin in the APTT and TT assays [9]. Calcium spirulan also exhibits antithrombin activity by activation of heparin cofactor II, an inhibitor of thrombin, thus by a mechanism that is different from that of heparin $[12,13]$. In 2007, Lee et al suggested that sodium spirulan might have beneficial effects as an anticoagulant agent on the blood coagulation fibrinolytic system [14]. This biological effect is dependent on molecular weight and/or sulphate content. Sodium spirulan can function as precursors of the agents that prevent atherosclerosis by inhibiting the proliferation of the arterial smooth muscle cells, as heparin for which the effect is not dependent on the anticoagulant activity, without exhibiting any toxic effects on the vascular endothelial cell layers [15]. Replacement of the sodium ion with calcium one generally maintains the biological activities of spirulan. However, removal of the ion or desulphation reduces the activities ; thus, the effect on the prevention of atherosclerosis requires a molecular mass of 14,700 or more, sulphate group and sodium or calcium ion [15].

\subsection{Other cyanobacteria}

Cyanobacteria of the genera Aphanocapsa, Cyanothece, Gloeothece, Synechocystis, Phormidium, Anabaena and Nostoc are able to produce sulphated polysaccharides containing uronic acids [5, 6]. Applications of cyanobacterial polysaccharides have been poorly investigated in the biomedical field except as antiviral agents $[10,14,16]$

\section{$2 \quad$ Heparin-like Entities from Marine Bacteria}

A number of microbial extracellular polysaccharides are produced on an industrial scale. For a review, you can see the book edited by Rehm in 2009 [17]. Xanthan (from Xanthomonas campestris), gellan (Sphingomonas paucimobilis) are widely used in food applications. Other well-known polysaccharides produced by bacteria, all non marine, include cellulose, dextran, curdlan, alginates, succinoglycans, hyaluronic acid [18-20]. Although no microbial strain produces heparin, a strain of Escherichia coli serotype K5 does form a capsular polysaccharide in which the disaccharide repeat unit is essentially a form of desulphatoheparin or $\mathrm{N}$-acetyl heparosan [21]. Chitin, the most abundant marine polysaccharide, has been extensively studied, itself or its derivative (chitosan), for its biomedical applications in particular as blood anticoagulant after chemical sulphation [22-24]. It is widely distributed in crustaceans, insects, fungi, and yeast but it is not produced by prokaryotes and is therefore not within the scope of this chapter. In the course of the discovery of novel polysaccharides of biotechnological interest, marine environment and 
especially, deep-sea hydrothermal vents offer a relevant source of a variety of new microorganisms and innovant polysaccharides.

\subsection{The marine biodiversity}

The marine environment covers more than $70 \%$ of the earth's surface, that is 361 millions $\mathrm{km}^{2}$ for an average depth of $3800 \mathrm{~m}$. Therefore, it represents a large reservoir of micro-organisms [25]. Still the marine biodiversity is a largely underexplored field [26] offering great opportunities in terms of chimiodiversity [27]. This makes marine microorganisms an attractive area for the search of new biomolecules.

A great variety of habitats exists all over the ocean, depending on environmental conditions such as water temperature, pressure and organic and mineral composition. The deep sea is the largest habitat on earth, but it is also the most difficult environment in which to survive because of the extreme conditions. Deep-sea environments are characterized by low temperature $\left(1-2^{\circ} \mathrm{C}\right)$, high pressure $(1 \mathrm{MPa}$ more every $100 \mathrm{~m})$, high-salt and low-nutrient conditions. They were once considered as a biological desert.

In contrast, deep-sea hydrothermal vents, which represent only a small portion of the whole ocean, are real "oases". They were discovered on oceanic geologic ridge such as those of the Galapagos and the Pacific East (2500 m of depth) as well as the mid-atlantic ridge but also at the level of the oceanic basins where appear tectonic activities e.g. the Guaymas ($2000 \mathrm{~m})$ and the North-Fijian $(-2000 \mathrm{~m})$ basins. Because of the high temperature of the salt water in the contact of the magma, waters which go out of these hydrothermal springs are extremely mineralised ; insoluble metal salts form chimneys called smokers. The stream which goes out can border $350^{\circ} \mathrm{C}$ while some centimeters farther, the temperature of the water is close to $2^{\circ} \mathrm{C}$. These ecosytems are characterized by the development, around the smokers, of a dense population of invertebrates based on heterotrophic and autotrophic bacterial communities. Micro-organisms exist as free in the water column or as colonizing animal and mineral surfaces.

It has been postulated that life on Earth originated at a deep sea vent [28, 29]. From the marine hydrothermal springs were isolated the micro-organisms among which the phylogeny and the metabolisms can be new and very diverse (Brittany Culture Collection : http://www.ifremer.fr/souchotheque). The number ceaselessly increasing of these newly described micro-organisms as well as the evidence, by molecular analytical methods, of new phyla of not cultured micro-organisms show the archae and bacterial diversity in the deep oceanic environments [30]. These bacteria arouse a big biotechnological interest for the isolation of biomolecules because of the particular properties of their cellular machinery. In a metagenomic studies review, Siezen and Wilson [31] report that deep-sea microbial communities are enriched in genes, among others, encoding polysaccharide biosynthesis. Most of the sequenced culturable micro-organisms from the deep-sea excluding hydrothermal vents are Alteromonadales from the Gammaproteobacteria [31]. Among mesophilic strains from deep-sea hydrothermal vents, Ifremer teams have also isolated mainly Alteromonadales in particular Alteromonas and Pseudoalteromonas genus [32,33] and a Vibrio strain, Vibrio which are also widely distributed in marine environments [34] .

From these microbial taxonomic groups, glycopolymers biosynthesis has been brought to light. Bacterial polysaccharides (PS) are either presents in the cellular wall as essential constituent of lipopolysaccharides (LPS), or as capsular material (CPS) that closely surrounds the producing microbial cell and bound outside of the cell or as material that is released more widely into the surrounding environment as a dispersed slime as exopolysaccharide (EPS) [35]. Their role has been reviewed by Mancuso Nichols et al [36]. They play an important 
role in the interaction between bacteria and their environment, participating in the cellular attachment and adhesion to surfaces, increasing survival compared with growth in an unattached state. Polysaccharides form a layer that protects cells against toxic compounds or against digestion by other organisms. PS may also prevent cell from desiccation or damage. The ultrastructural network protects cells and facilitates cellular interactions. Polysaccharides from marine bacteria, living in extreme conditions, usually show peculiar chemical features as a consequence of their adaptation to their environment.

Molecules produced by bacteria have the advantage not to depend on climatic and ecological conditions or on seasonal physiological variations which can affect their plant counterparts. Large amounts of the starting polymer can be obtained by biotechnological methods.

\subsection{Sulphated polysaccharides are produced by some marine bacteria}

Various animal glycosaminoglycans exhibit powerful blood anticoagulant activity. Anti-coagulant activities of polysaccharides have been described to depend mainly on the sulphate groups present within the molecule even if some other structural characteristics such as the polyanionic feature or the molecular weight modulate the biological activity [37].

Although no marine micro-organism produces heparin, some of them synthesizes polysaccharides sometimes sulphated with neutral or hexosamine sugar and uronic acids. Most of the EPS-producing marine bacteria belong to the genus Vibrio, Flavobacterium, Pseudomonas, and Alteromonas or Pseudoalteromonas [38]. Although common in animal cells, sulphated carbohydrates are rare in prokaryotes, having been reported so far in rhizobia i.e. Sinorhizobium meliloti [39] or Mesorhizobium loti [40] as well as Azospirillum brasilense Sp7 [41], Mycobacterium [42]. As far as marine bacteria are concerned, sulphated polysaccharides have been described in Pseudomonas species [43] and in some marine Alteromonas strains or Pseudoalteromonas species [44-46]. This Alteromonadaceae family seems rich in sulphated EPSs. However, Ivanova et al [47], Nazarenko et al [48], Zubkov et al [49], Perepelov et al [50] and Saravanan and Jayachandran [51] have described polysaccharides of some marine Alteromonas or Pseudoalteromonas species composed of different neutral sugars as well as hexosamine and uronic acid residues but there was no evidence of sulphate groups. Some of these polysaccharides contain novel sugar residues emphasizing the chimiodiversity of marine micro-organisms [49, 50]. The diversity of the structures of polysaccharides from Pseudoalteromonas and Shewanella sp. both belonging to the Alteromonadaceae family has been reviewed by Nazarenko et al [52]. Some sulphates have also been detected in Marinobacter sp. extracellular polymeric substances but there is no evidence of the sulphated status of the polysaccharides which compose these exopolymeric substances [53] even if sulphated polysaccharide has also been described in a Marinobacter strain [38].

Our studies of numerous isolates from deep-sea hydrothermal vents revealed a few polymers with interesting properties. They are high molecular weight carbohydrate polymers, either linear [34, 54] or highly branched [44, 45, 55]. Most of them have high uronic acid content, and bear different substituing groups (sulphate, pyruvate, lactate)[56, 57]. Pseudoalteromonas Strain HYD721, Alteromonas infernus [33] and Alteromonas macleodii subsp. fijiensis biovar deepsane [58] can produce sulphated polysaccharides (HYD721, GY785 and HYD657 respectively) (Figure 1) [44, 45]. GY785 is a water soluble acidic heteropolysaccharide composed of glucose, galactose, glucuronic and galacturonic acids $(1: 1: 0.7: 0.4)$ and $3 \%(\mathrm{w} / \mathrm{w})$ sulfur content corresponding to $9 \%$ sulphate groups [45]. The 
structure of polysaccharide HYD657 has not been elucidated yet and is currently in progress in Ifremer but sulphate content determination has shown a level of $9 \%$ sulphate $(\mathrm{w} / \mathrm{w})$.

Various animal glycosaminoglycans exhibit powerful blood anticoagulant activity. Anti-coagulant activities of polysaccharides have been described to depend mainly on the sulphate groups present within the molecule even if some other structural characteristics such as the polyanionic feature or the molecular weight modulate the biological activity [37].

Although no marine micro-organism produces heparin, some of them synthesizes polysaccharides sometimes sulphated with neutral or hexosamine sugar and uronic acids. Most of the EPS-producing marine bacteria belong to the genus Vibrio, Flavobacterium, Pseudomonas, and Alteromonas or Pseudoalteromonas [38]. Although common in animal cells, sulphated carbohydrates are rare in prokaryotes, having been reported so far in rhizobia i.e. Sinorhizobium meliloti [39] or Mesorhizobium loti [40] as well as Azospirillum brasilense Sp7 [41], Mycobacterium [42]. As far as marine bacteria are concerned, sulphated polysaccharides have been described in Pseudomonas species [43] and in some marine Alteromonas strains or Pseudoalteromonas species [44-46]. This Alteromonadaceae family seems rich in sulphated EPSs. However, Ivanova et al [47], Nazarenko et al [48], Zubkov et al [49], Perepelov et al [50] and Saravanan and Jayachandran [51] have described polysaccharides of some marine Alteromonas or Pseudoalteromonas species composed of different neutral sugars as well as hexosamine and uronic acid residues but there was no evidence of sulphate groups. Some of these polysaccharides contain novel sugar residues emphasizing the chimiodiversity of marine micro-organisms [49, 50]. The diversity of the structures of polysaccharides from Pseudoalteromonas and Shewanella sp. both belonging to the Alteromonadaceae family has been reviewed by Nazarenko et al [52]. Some sulphates have also been detected in Marinobacter sp. extracellular polymeric substances but there is no evidence of the sulphated status of the polysaccharides which compose these exopolymeric substances [53] even if sulphated polysaccharide has also been described in a Marinobacter strain [38].

Our studies of numerous isolates from deep-sea hydrothermal vents revealed a few polymers with interesting properties. They are high molecular weight carbohydrate polymers, either linear [34, 54] or highly branched [44, 45, 55]. Most of them have high uronic acid content, and bear different substituing groups (sulphate, pyruvate, lactate)[56, 57]. Pseudoalteromonas Strain HYD721, Alteromonas infernus [33] and Alteromonas macleodii subsp. fijiensis biovar deepsane [58] can produce sulphated polysaccharides (HYD721, GY785 and HYD657 respectively) (Figure 1) [44, 45]. GY785 is a water soluble acidic heteropolysaccharide composed of glucose, galactose, glucuronic and galacturonic acids (1:1:0.7:0.4) and 3\% (w/w) sulfur content corresponding to $9 \%$ sulphate groups [45]. The structure of polysaccharide HYD657 has not been elucidated yet and is currently in progress in Ifremer but sulphate content determination has shown a level of $9 \%$ sulphate $(\mathrm{w} / \mathrm{w})$.

EPS composed of neutral sugar, hexosamine and or uronic acid residues have also been described in Vibrio strains such as $V$. harveyi [38], V. diabolicus [59], V. furnissii [60], V. alginolyticus [61]. They do not bear any sulphate groups but their structure may show some homology with glycosaminoglycans especially hyaluronic acid (Figure 2). The first species of Vibrio to be isolated from a vent sample was a mesophile that secretes an innovative EPS of potential medical interest for its chemical resemblance to heparin. The EPS HE800 secreted by Vibrio diabolicus has a linear repetitive unit constituted by four residues : two of glucuronic acid, one $\mathrm{N}$-acetyl-glucosamine and one $\mathrm{N}$-acetyl-galactosamine. It is a structural analogue of heparan sulphate or heparin with the succession of glucuronic acid and hexosamine residues ; however, it does not have sulphate groups. Its molecular weight is about $10^{6} \mathrm{~g} \mathrm{~mol}^{-1}$ and varies from one production lot to another [34, 54]. 
A : GY785 exopolysaccharide

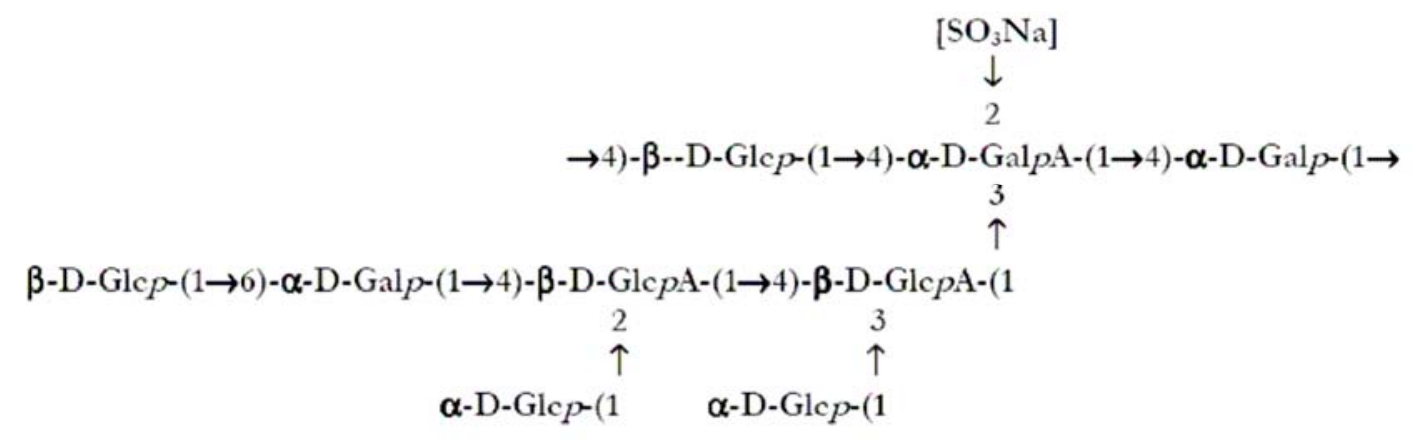

B : HYD721 exopolysaccharide

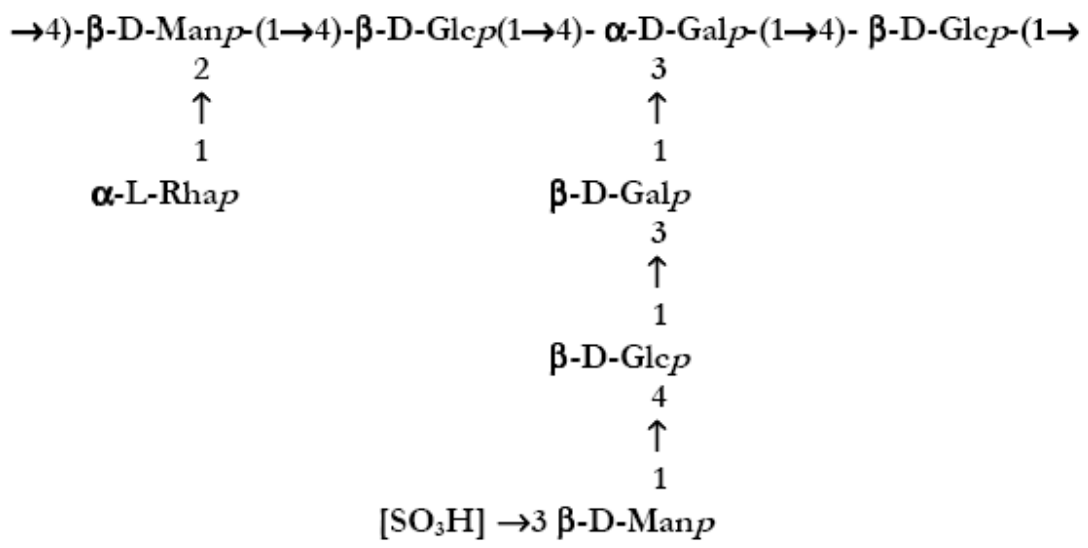

Figure 1 : Structures of the repeating unit of the main exopolysaccharides produced by the marine microorganims Alteromonas infernus (A) and Pseudoalteromonas strain HYD721 (B)

HE800

$\rightarrow 3)-\beta-D-G l c p N A c-(1 \rightarrow 4)-\beta-D-G l c p A-(1 \rightarrow 4)-\beta-D-G l c p A-(1 \rightarrow 4)-\alpha-D-G a l p N A c-(1 \rightarrow$

Hyaluronic acid

$\rightarrow 3)$-3-D-GlcpNAc-(1 $\rightarrow$ 4)-13-D-GlcpA-(1 $\rightarrow$

Figure 2 : Osidic sequence of the repeating unit of the polysaccharides HE800 and hyaluronic acid. 


\subsection{Native polysaccharides are bioactive}

Only a few of marine bacterial polysaccharides having GAG-like biological activities have been reported. Native EPS exhibit interesting biological activities such as efficient bonehealing material for HE800. This EPS secreted by Vibrio diabolicus was evaluated on the restoration of bone integrity in experimental animal model and was demonstrated to be a strong bone-healing material without inducing any inflammatory reaction. Moreover the new bone was histologically normal and the new vascularization was significant [62-64]. However, high molecular weight polysaccharides even if they bear sulphate do not present anticoagulant properties like heparin [65]. Thus these high molecular weight polysaccharides could function as a material for the regeneration of a wide variety of tissues for both wound care and the regeneration of damaged or diseased organs. Another Vibrio polysaccharide has been shown to have antitumor activity [66].

\subsection{Polysaccharides may be modified to obtain heparin-like entities}

Many polysaccharides exhibit useful properties when they undergo structural modifications. Owing to this, they may find varied applications in the food, pharmaceutical and other industries. Structural derivatives of extracellular polymers (EPS) with unusual structures produced by marine bacteria isolated from hydrothermal deep-sea vents have been prepared by chemical modifications to design compounds with better activity and specificity. Marine polysaccharides are suitable as starting materials to synthesize heparin-like drugs and sulphated or over-sulphated derivatives have been prepared. Modification processes giving GAG-mimes (semi-synthetic sulphated polysaccharides) are up to now chemical : acid hydrolysis [67], radical depolymerisation [68], N-deacetylation with sodium hydroxyde [69], sulphation [70].

Heparin-like derivatives was obtained from chemical modifications of the native GY785 EPS secreted by Alteromonas infernus [65]. This EPS is naturally sulphated (9\% sulphate groups w/w). After its chemical over-sulphation, only the free $\mathrm{OH}$ groups can bear a sulphate group. Two depolymerization processes were used to obtain homogeneous LMW and over-sulphated derivatives (20-30 $10^{3} \mathrm{~g} / \mathrm{mol}$ and sulphate content 20-40\%). The compounds generated by radical process were more homogeneous than those obtained by acid hydrolysis with respect to molecular mass. The derivatives obtained after over-sulphation and depolymerisation were compared to heparin, anticoagulant activity was detected in oversulphated derivatives, but not in the native EPS. The free radical depolymerised and oversulphated derivative inhibited thrombin generation in both contact-activated and thromboplastin-activated plasma, showing a prolonged lag phase only in the contact-activated assay. Affinity co-electrophoresis studies suggested that a single population of polysaccharide chains binds to antithrombin and that only a subpopulation strongly interacts with heparin cofactor. The preparation of new heparinoids or heparin-like entities from other EPS secreted by strains isolated from deep-sea vents have been undertaken. These LMW over-sulphated derivatives presenting differences in structural features were endowed with original anticoagulant properties compared to heparin. They presented a lower anticoagulant activity than heparin so could be promising new antithrombotic drugs without major bleeding risk [71]. 
All marine algae contain sulphated wall polysaccharides, whereas such polymers are not in terrestrial plants. The proportion of highly acidic polysaccharides is greater in the outer regions of the cell wall and in the outer cellular layers of the thallus. Heparin-like entities, with biological properties similar to heparin rather than similarity of stucture, extracted from marine algae have been well described for the last 60 years. Sulphated polysaccharides from the three major divisions of marine algae Rhodophyta, Phaeophyta and Chlorophyta have been studied to explore their potential as a cheap and safe source of a new type of heparinoids or heparin-like entities. Among the numerous studied algal polysaccharides, the fucoidans, a minor matrix component in brown algae - the byproducts of alginate production in food and cosmetic industries -, can be considered as the "marine heparin". This algal sulphated polysaccharide family with complex, heterogeneous structures shares a lot of biological properties with heparin, especially low molecular weight homogeneous fucoidan preparations. The LMW fucoidan with a high arterial antithrombotic activity presents both low anticoagulant effect and haemorrhagic risk, this compound is a promising antithrombotic drug which could be of interest in preventing restenosis or potentiating neovascularization of ischaemic areas.

\subsection{Heparin-like Entities from Macroalgae}

Algal sulphated polysaccharides are complex and high molecular mass molecules (molecular mass ranges between $10^{5}$ and $>10^{6}$ ) with no clear evidence of repeating units in their structure. These anionic macromolecules are essentially found in three major divisions of marine algae : Rhodophyta (red algae), Phaeophyta (brown algae) and Chlorophyta (green algae). The sulphated polysaccharides extracted from red algae are galactans consisting entirely of galactose units (carrageenans and agars), they are mainly linear sulphated homopolysaccharides. The sulphated polysaccharides found in brown algae are more complex, they are highly branched heteropolysaccharides. According to the species of brown algae, the sulphated polysaccharides are more or less complex and often described in three groups. A first group, fucoidans or homofucans, is highly branched and primarily composed of L-fucose units with small contents in D-xylose, D-galactose, D-mannose and uronic acid units. A second group, ascophyllans, are xylofucoglycuronans with large proportions of Dxylose and uronic residues. The third group contains glycuronogalactofucans or glycuronofucogalactans in which galactose becomes preponderant over fucose and uronic acid units. Often fucoidan fractions contain a small amount of proteins, probably covalently attached, and suggesting that the brown algal sulphated polysaccharides exist in vivo as proteoglycans. The sulphated polysaccharides in Chlorophyta are highly branched heteropolysaccharides made up of D-xylose, L-rhamnose, galactose and glucuronic acid with three main groups glucuronoxylorhamnans, glucuronoxylorhamnogalactans and xyloarabinogalactans. Some of the green algal sulphated polysaccharides are found covalently attached to a protein and they are characterized as proteoglycans [1-3].

\subsubsection{Galactan family from Rhodophyceae}

The composition and structure of the sulphated galactans found in Rhodophyta vary according to the algal genus; they are known commercially such as agar and carrageenan. Galactans are usually extracted for food application (e.g. jelly candies and canned meats for 
agars and frozen dessert stabilizers for carrageenans) and industrial applications such as important life science applications (e.g. chromatography and microbial and cell cuture media for agars and agaroses derived from agars). Sulphated polysaccharides from red algae have been well described by many workers for their antiviral activities towards viruses responsible for human infection diseases [4-7]. However over 40 species of red algae have been also studied for their anticoagulant activities. A considerable structural variation in the red agal sulphated galactans occurs among different species from different environments. Consequently it is often very difficult to class them as agar-type or carrageenan-type.

The agars are mainly extracted from Gelidium, Gracilaria, Pterocladia, Gracilariopsis and Porphyra. They are low sulphated galactans (from $2 \%$ to $5 \%$ of sulphate groups) and the disaccharidic repeating unit is a 1,4-linked $\alpha$-D-galactose and 3,6-anhydro- $\alpha$-L-galactose (agarobiose). Consequently very few studies on biological activities and especially anticoagulant properties of native agars are described due to their low sulphate content.

A sulphated galactan from Gelidium crinale was studied by Pereira et al. According to its algal origin, this sulphated galactan can be considered as agar, it shows a very heterogeneous sulphation pattern and presents a very low anticoagulant activity $(65 \mathrm{IU} / \mathrm{mg}$ compared with a heparin standard found at $180 \mathrm{IU} / \mathrm{mg}$ in the APTT clotting assays). This low anticoagulant activity is probably due to its low proportion of sulphate groups more than their distribution on the osidic backbone [8].

Carrageenans mainly extracted from Chondrus, Gigartina, Euchema and Hypnea are highly sulphated galactans (from 20 to $40 \%$ of sulphate groups). Carrageenans are divided into 3 groups with regard to differences of solubility and also the content and the position of sulphate groups on the galactose unit. The kappa- and iota-carrageenans have a disaccharidic repeating unit alterning 1,3-linked $\alpha$-D-galactose and 1,4 linked 3,6-anhydro- $\beta$-D-galactose (carrabiose) substituted with varying positions and percentages of sulphate groups. For kappa, the galactose unit is 4-sulphated ( $25 \%$ of sulphate groups) and for iota, the galactose unit is also 4-sulphated as well as the 3,6-anhydrogalactose unit is 2-sulphated (32\% of sulphate groups). The lambda-carrrageenan disaccharidic repeating unit is composed of alterning 2sulphated 1,3 linked $\alpha$-D-galactose and 2,6 disulphated 1,4-linked $\beta$-D-galactose (35\% of sulphate groups). Among the different groups of carrageenans, the lambda is the most hydrosoluble. Contrary to the kappa- and iota-, the lambda-carrageenan is a non-gelling polysaccharide and presents a proportion of sulphate groups close to that found in glycosaminoglycans. The lambda-carrageenan is described as more toxic than the kappa- but this toxicity seems dependent of the molecular weight.

In 1962, Hawkins and Leonard decided to study carefully the anticoagulant activities of the lambda- and kappa-types of carrageenins or carrageenans extracted from Chondrus crispus with the intention to clarify the previous studies [9]. Both in vitro and in vivo assays were performed. For the in vivo effect, the products were administered intravenously into dogs at different doses and blood collected at different times after the injection (from 0.5 to 2 hours). At $5 \mathrm{mg} / \mathrm{kg}$ of lambda-carrageenan and $0.5 \mathrm{mg} / \mathrm{kg}$ of heparin, the same prolongations in both clotting times and thrombin times were observed $1 / 2$ hour after the injection. Kappacarrageenan had no effect. In vitro anticoagulant assays performed in human and dog plasma showed a same effect for lambda-carrageenin and heparin in thrombin time at $10 \mu \mathrm{g} / \mathrm{mL}$ and 1 $\mu \mathrm{g} / \mathrm{mL}$, respectively. So this study showed as with heparin, an antithrombic property of the lambda-carrageenan 10fold lower than heparin. In 1965, Anderson and Duncan confirmed by in vivo experiments in the rabbit and in vitro assays (prothrombin time and thrombin time) that the lambda-carrageenan is more anticoagulant than the corresponding kappa-carrageenan. The lambda-carrageenan is also more toxic than the kappa-carrageenan [10]. 
Guven et al in 1991, compared different carrageenan-types extracted from Grateloupia dichotoma; the highest anticoagulant activity measured in vitro by clotting assays was found with lambda-type [11].

Carlucci et al in 1997, described both antiviral and anticoagulant activities of carrageenans extracted from Gigartina skottsbergii [12]. Both the kappa- and lambda-types have a high molecular weight $\left(10^{5}\right)$. The lambda-type has a higher content of sulphate groups (40\%) than the kappa-type (30\%). These compounds were not toxic and their anticoagulant activities were determined in vitro by the thrombin time (TT). The kappa- and lambdacarrageenans can prolong the TT. The concentrations required to double the control time (15.6 s.) were around $5 \mu \mathrm{g} / \mathrm{ml}$ for the lambda-type and $200 \mu \mathrm{g} / \mathrm{ml}$ for the kappa-type. The lambdatype presents the highest anticoagulant effect and at $50 \mu \mathrm{g} / \mathrm{ml}$ the TT is above $180 \mathrm{~s}$. A recent publication described also the anticoagulant activity of a native lambda-carrageenan extracted from Tichocarpus crinitus [13]. The anticoagulant activity of the non-gelling fraction was measured in vitro using the activated partial thromboplastin time (APTT). At $100 \mu \mathrm{g} / \mathrm{ml}$, the APTT was prolonged and the coagulation time measured at $343 \mathrm{~s}$. (58.7 s. for the control time).

Some groups decided to obtain homogeneous low molecular fractions in order to isolate a better characterised product and improve its specificity. The group of Yamada in 1997 modified chemically carrageenans in order to obtained lower molecular weight fractions and tested their in vitro anticoagulant activity using the APTT. The native lambda-type is more anticoagulant than the kappa- and iota-types and a decrease of the anticoagulant activity was observed with the decrease of the molecular weight. The oversulphation of the depolymerised carrageenans can increase or maintain the anticoagulant activity [14]. Opoku et al showed that the chemical oversulphation of a kappa-carrageenan can increase its anticoagulant activity (30-fold) but the oversulphated kappa-carrageenan was 10-fold less effective than unfractionated heparin with the same percentage of sulphate as heparin [15].

The mechanism of anticoagulant activity of carrageenans has been described, the carrageenans inhibit thrombin through the catalysis of antithrombin [2].

The anticoagulant activity of a low molecular weight fraction obtained by free radical depolymerisation of the sulphated galactan extracted from Schizymenia binderi was studied by Zuniga et al in 2006 [16]. In this study, the very low molecular weight (LMW) fraction (MW 8,500 ; sulphate 25\% and a mixture of agaran and carrageenan) was less active than the corresponding native polysaccharide, its chemical sulphation increased the activity. In thrombin time, the concentrations required to observe the same prolongation were $1.5 \mu \mathrm{g} / \mathrm{ml}$ of heparin, $50 \mu \mathrm{g} / \mathrm{mL}$ of native polysaccharide, $150 \mu \mathrm{g} / \mathrm{mL}$ of LMW fraction and $50 \mu \mathrm{g} / \mathrm{mL}$ of oversulphated LMW fraction. Pushpamali et al attempted to hydrolyse a sulphated polysaccharide from the red seaweed Lomentaria catenata by fermentation of seaweeds. After fermentation, the molecular weight of the sulphated polysaccharides remains high (from $10^{5}$ to $5 \times 10^{5}$ ) and its sulphate content is close to $22 \%$ [17]. Recently the Mourao's group performed an extensive study on the anticoagulant and antithrombotic properties of algal sulphated galactans from the red alga Botryocladia occidentalis $[18,19]$. The analysis of the native product showed an unusual dual effect in rat model of venous thrombosis. In order to avoid this dual effect, low molecular weight derivatives were prepared by acid hydrolysis. A very low molecular weight fraction (MW $5 \times 10^{3}$ ) lost this dual effect and its effect was similar to unfractionated heparin (UFH) in venous thrombosis with very weak anticoagulant effect. This product had little activity in arterial thrombosis in rat. This study demonstrates that better specific effect or dose-related effect can be obtained by the preparation of LMW derivatives from heterogeneous products. 


\subsubsection{Fucoidan family from Phaeophyceae}

Fucoidan, first described by Kilin in 1913, was originally a member of the sulphated polysaccharides found in Phaeophyceae for which the general name of fucans was given and including a family of compound as fucoidin, fucoidan, ascophyllan, sargassan and glucuronoxylofucan. Fucoidan is a highly sulphated polysaccharide (30-40\%) as heparin but contrary to heparin, fucoidan neither contains $\mathrm{N}$-acetylated nor $\mathrm{N}$-sulphated groups. Fucoidan is primarily composed of 4 -sulphated 1,2-linked $\alpha$-L-fucose with branching or sulphate group at position 3 .

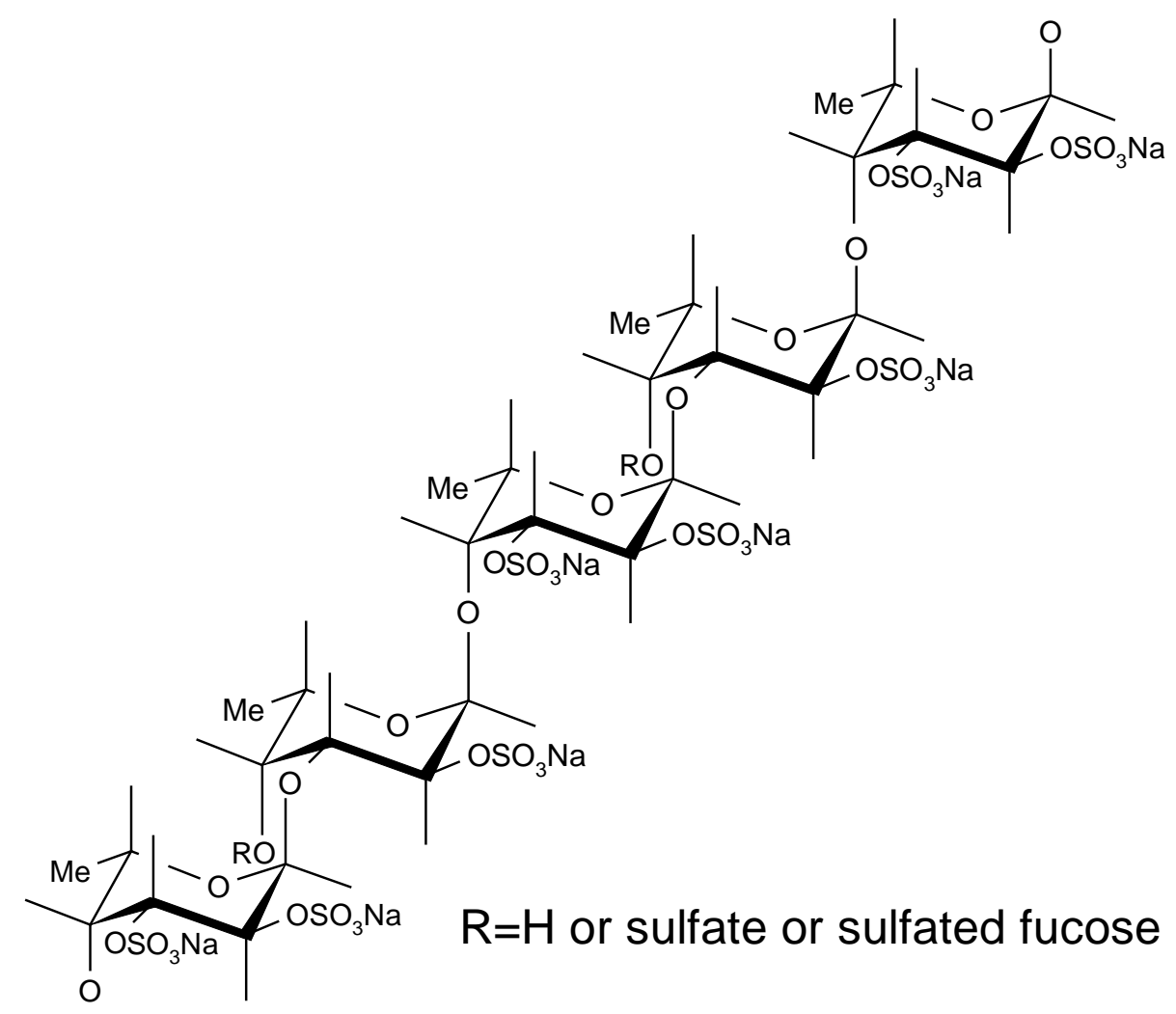

\section{Figure 3. Structure of sulphated oligofucans constitutive of a low molecular weight fraction from Ascophyllum nodosum. From Chevolot et al, 2001 [20].}

The biological activities of fucoidan depend on the structure of the starting material, the purification process, its structural heterogeneity and molecular mass dispersion. Fucoidan have a wide spectrum of activity in biological systems [21].

\section{Anticoagulant activity (or antithrombin activity).}

In 1941 and 1957, the anticoagulant activity of heterogeneous extracts rich in fucoidan were reported by Kimura et al and Springer et al, respectively [22, 23]. Then different extracts more or less purified from brown algae presenting variable molecular mass have been studied for their biological activities. In 1985, Deaconsmith et al studied heterogeneous algal extracts from different genera of Phaeophyceae (Laminaria, Fucus, Ascophyllum ...). They showed an 
inhibiting effect on the thrombin time performed with plasma and also pure fibrinogen and suggested an immediate inhibition of thrombin activity [24]. In 1989, different research teams published the anticoagulant activity of fucose-containing sulphated polysaccharides from various brown algae. First, Nishino et al isolated different sulphated polysaccharidic fractions obtained first by hot-water extraction from Ecklonia kurome followed by successive fractionation steps using anion-exchange and gel filtration chromatographies. A low molecular weight $(21,000 \mathrm{~g} / \mathrm{mol})$ homogeneous fraction was obtained, it contains mainly fucose units and ester-sulphate groups. This highly purified fucoidan possessed a high anticoagulant activity especially in APTT and no anti-factor Xa activity was detected [25]. Then, Grauffel et al prepared a relatively LMW fucan fraction $(50,000 \mathrm{~g} / \mathrm{mol})$ from different species (Pelvetia canaliculata, Fucus vesiculosus, Laminaria digitata, Sargassum muticum and Ascophyllum nodosum) and investigated the anticoagulation mechanism by checking the involvement of the antithrombin III (AT III) or other plasma inhibitors [26]. According to the species, the anticoagulant activity was found very related to chemical composition and extraction conditions. Direct interaction between fucan and thrombin seems largely responsible for the kinetic effect of thrombin inactivation but inactivation of thrombin was accelerated when LMW fucan fraction was incubated with AT III (the predominant inhibitor of thrombin in plasma). This kinetic effect of thrombin inactivation by AT III was less important with fucoidan than with heparin. No neutralization of factor Xa was observed in the presence of this fucan fraction. Finally, Church et al studied the interaction of fucoidan with heparin cofactor II (HC II), AT III and thrombin using a commercial heterogeneous HMW fucoidan extracted from Fucus vesiculosus $(100,000 \mathrm{~g} / \mathrm{mol})$ [27]. He showed that the antithrombin action of fucoidan (ex vivo in a plasma system) is mediated through HC II and not through AT III and this correlates well with the antithrombin effect of fucoidan observed in vitro.

In 1991, Colliec et al confirmed these results using a homogeneous LMW fucoidan extracted from Pelvetia canaliculata $(20,000 \mathrm{~g} / \mathrm{mol})$ [28]. This LMW fucoidan was anticoagulant in vitro and as potent on the prolongation of APTT and TT as heparin, with a concentration of 50 times higher (on a weight to weight basis). Fucoidan was a weak inhibitor of thrombin generation (100 times lower than heparin). By comparison to Chrurch's data (using a HMW fucoidan) [27], Colliec et al found roughly a same enhancement on the rate of thrombin inhibition by HC II $\left(1.510^{8} \mathrm{M}^{-1} \mathrm{~min}^{-1}\right.$ and $3.810^{8} \mathrm{M}^{-1} \mathrm{~min}^{-1}$ with $10 \mu \mathrm{g} / \mathrm{mL}$ of HMW fucoidan and LMW fucoidan, respectively) but a stronger inhibition mediated by AT III (3 $10^{8} \mathrm{M}^{-1} \mathrm{~min}^{-1}$ with $10 \mu \mathrm{g} / \mathrm{mL}$ of LMW fucoidan and $5.710^{7} \mathrm{M}^{-1} \mathrm{~min}^{-1}$ with $30 \mu \mathrm{g} / \mathrm{mL}$ of HMW fucoidan). On the other hand, Church et al observed a weak factor Xa inhibition by AT III in the presence of the HMW fucoidan at very high concentration $(500 \mu \mathrm{g} / \mathrm{mL})$, while at this high concentration the LMW fucoidan is not able to produce noticeable inhibition. In conclusion, this LMW fucoidan exerts its anticoagulant activity by enhancing thrombin inhibition in the presence of either AT III or HC II. Among the known anticoagulant sulphated polysaccharides, this LMW fucoidan appears to be the only one, as potent on the formation of an AT III-thrombin complex, as of an HC II-thrombin complex. In fact, heparin requires much higher concentrations to enhance the activity of HC II than the one of AT III. On the contrary, pentosan polysulphate and dermatan sulphate are mainly active via an HC II pathway. Moreover, the absence of factor Xa inactivation by this LMW fucoidan, correlated with its low viscosity (compared to HMW fucoidan) and its high thrombin inactivation, could be an important feature for further clinical use, according to some studies. Indeed, it has been demonstrated that LMW heparin fragments, with high factor Xa inhibition and negligible thrombin inhibition activity, are poor antithrombotic agents.

The same year, Nishino et al showed the relationship between both molecular weight and sulphate content of fucoidan and its antithrombin effect. Its antithrombin activity in the 
presence of HC II was improved with increase in its molecular weight and reduced with decrease in its sulphate content [29].

In 1992 and 1993, Soeda et al reported that fucoidan in vitro stimulated tissue plasminogen activator (t-PA) catalysed plasminogen activation and prevented the formation of fibrin polymer according to its degree of sulphation [30, 31]. And they also reported that the in vitro abilities of oversulphated fucoidan to stimulate t-PA catalysed plasminogen activation and to potentiate thrombin inhibition by AT III or HC II decreased with a decrease in its molecular size. And for the first time, the therapeutic benefit of fucoidan for the prevention of thrombus formation in hyperlipemia was described in an animal model (endotoxin-induced hepatic vein thrombosis in the hyperlipemic rat model).

\section{Antithrombotic activity.}

Then after this Soeda's publication, the antithrombotic activity of fucoidan has been widely described in different animal models. In 1995, Mauray et al showed the venous antithrombotic and anticoagulant activities of a homogeneous LMW fucoidan extracted from Ascophyllum nodosum $(20,000 \mathrm{~g} / \mathrm{mol})$ [32]. In a Wessler model of venous thrombosis, the LMW fucoidan injected intravenously to rabbits exhibited antithrombotic activity and the dose which inhibited $80 \%$ of mean thrombus weight $\left(\mathrm{ED}_{80}\right)$ was $1.8 \mathrm{mg} / \mathrm{kg}$, compared to a heparin $\mathrm{ED}_{80}$ of $0.1 \mathrm{mg} / \mathrm{kg}$. At this $\mathrm{ED}_{80}$, the antithrombotic effect of the LMW fucoidan persisted longer than that of heparin (30 min versus $15 \mathrm{~min}$ ) but the ex vivo measured anticoagulant effect was related to an haemorrhagic risk. In 1999, Millet et al reported the antithrombotic and anticoagulant activities of a very LMW fucoidan from Ascophyllum nodosum $(8,000$ $\mathrm{g} / \mathrm{mol}$ ) by subcutaneous route [33]. In Wessler model, this LMW fucoidan exhibited doserelated venous antithrombotic activity, with an ED80 of about $20 \mathrm{mg} / \mathrm{kg}$, two hours after a single subcutaneous injection. At the same antithrombotic activity, LMW fucoidan exhibited a lower effect on ex vivo coagulation tests, and a lower prolongation of the bleeding time than the LMW heparin (dalteparin), which corresponded to a weaker haemorrhagic effect.

Then, Colliec-Jouault et al [34] showed that LMW fucoidan (injected intravenously or subcutaneously) exhibited arterial antithrombotic properties in rabbit and rat at the same doses than in a venous thrombosis model $(1.8-2 \mathrm{mg} / \mathrm{kg}$ intravenous and $10-20 \mathrm{mg} / \mathrm{kg}$ subcutaneous). In the same arterial thrombosis models, both unfractionated heparin and LMW heparin have to be used at higher doses than in the Wessler venous thombosis model. Thus, the anticoagulant effect, the prolongation of the bleeding time and the haemorrhagic risk are much more pronounced, in these arterial thrombosis models, with heparins than with fucoidan. These results were confirmed recently by Durand, Helley et al in a rabbit model of arterial thrombosis [35]. Thrombosis was induced in femoral arteries by in situ induction of endothelial apoptosis and the animals treated by subcutaneous injection of $15 \mathrm{mg} / \mathrm{kg}$ of LMW fucoidan from Ascophyllum nodosum $(8,000 \mathrm{~g} / \mathrm{mol})$ and $2.5 \mathrm{mg} / \mathrm{kg}$ of LMW heparin (enoxaparin). LMW fucoidan appeared to be more effective than LMW heparin for preventing arterial thrombosis in this experimental model. LMW fucoidan also had lower haemorrhagic risk than LMW heparin. The plasma concentration of tissue factor pathway inhibitor (TFPI) was significantly increased after LMW fucoidan injection, whereas no change was observed after LMW heparin treatment.

This effect on TFPI was previously described for heparin, and by Girault et al for fucoidan; actually they showed that fucoidan induces TFPI release from cultured human umbilical vein endothelial cells, which may contribute to its antithrombotic effect [36]. In summary, the antithrombotic effect of LMW fucoidan may in part be explained by the observed effect on the tissue factor pathway. Previously, Tholarius et al reported that a heterogeneous HMW fucoidan prevented microvascular thrombus formation induced by 
endothelial damage in arterioles and venules in vivo. This protective effect of fucoidan is not attributable to inhbition of P- and L-selectin function but may instead be related to the anticoagulant capacity of fucoidan [37].

\section{Endothelial cell interaction.}

Endothelial wound repair is a crucial step to prevent rethrombosis and restenosis of a damaged arterial vessel wall. Besides its anticoagulant and antithrombotic effects, fucoidan can induce angiogenesis in vitro by modulating the proangiogenic properties of heparinbinding growth factors such as fibroblast growth factor-2 (FGF-2). In 1983, Glabe et al described a reversible disruption of cultured endothelial monolayers and found that fucoidin appears to bind at two distinct sites on endothelial monolayers. One site is inhibitable by heparin, while the other site seems to be specific for fucoidin. So these authors suggested that sulphated fucose-containing glycoconjugates may play a role in the adhesive interactions of endothelial cells [38]. The effect of a LMW fucoidan from Ascophyllum nodosum on the growth and migration of human umbilical vein endothelial cells was compared to heparin in the presence of human growth factors. Fucoidan modulated FGF-2 induced cell proliferation, in a way depending on FGF-2 concentration, whereas unfractionated heparin had an inhibitory effect [39]. Then it was described that LMW fucoidan from Ascophyllum nodosum can enhance FGF-2 induced tube formation of endothelial cells through $\alpha_{6}$ overexpression that was heparan sulphate dependent [40-42].

Other properties of LMW fucoidan from Ascophyllum nodosum could also be of interest against arterial thrombosis, as these molecules are able to enhance vascular tube formation as described above and to inhibit smooth cell proliferation and neointimal hyperplasia. LMW fucoidan and heparin share some similar mechanisms of action, such as smooth muscle cell growth inhibition, binding and internalisation [43]. This fucoidan with high affinity for smooth muscle cells reduced intimal hyperplasia in rabbit iliac artery in-stent restenosis model and may be potentially relevant for the treatment of in-stent restenosis [44]. Moreover, in rat model of critical hindblind ischemia, LMW fucoidan promoted therapeutic revascularization induced by FGF-2. LMW fucoidan promotes FGf-2 effects in vivo, suggesting its potential interest for use in vascular tissue repair and angiogenesis [45]. The inhibition of plateletneutrophil interactions by a HMW heterogeneous fucoidan was showed and this inhibition reduces adhesion and vasoconstriction after acute arterial injury by angioplasty in pigs [46]. In rat cardiac allograft model, the LMW fucoidan from Ascophyllum nodosum appeared very effective to prevent arterial and parenchymal lesions occurring in response to alloimmune injury. However this protective effect does not appear to depend on mobilization of bone marrow-derived cells [47].

\section{Neoangiogenesis induced by endothelial progenitor cells.}

Another effect of fucoidan is the ability to promote progenitor stem cell mobilization via the release of stromal-derived factor-1 (SDF-1) from heparan sulphate sites. This effect was previously described by Sweeney et al for HMW heterogeneous fucoidan and other glycosaminoglycans, such as dextran sulphates and chondroitin sulphate. Sweeney et al also indicated that plasma metalloproteinase MMP-9 significantly increases in response to intravenous injection of HMW fucoidan [48].

In constrast, LMW fucoidan from Ascophyllum nodosum did not induce an increase in MMP-9 level in vivo [45]. These results suggest that sulphated polysaccharides from the same family may exhibit different properties depending on their molecular weight. Boisson-Vidal et al reported that LMW fucoidan from Ascophyllum nodosum enhances the proangiogenic 
properties of endothelial progenitor cells and can mobilize bone marrow progenitor cells in peripheral blood, enhancing their recruitment to sites of active angiogenesis and increasing blood vessel formation $[49,50]$.

\section{Anti-inflammatory activity.}

Like proteoglycans, fucoidan interacts with a wide range of proteins and thus has pleiotropic properties including anti-inflammatory activity [51, 52]. More recently, Cumashi et al studied the biological properties of fucoidans obtained from nine species of brown algae. All fucoidans inhibited leucocyte recruitement in an inflammation model in rats [53]. In 2008, Medeiros et al reported that fucoidan from Lobophora variegata (Phaeophyceae, Dictyotales) inhibits leukocyte migration to the inflammatory site. Ear swelling caused by croton oil was also inhibited when polysaccharides form Fucus vesiculosus and Lobophora variegata were used. The polysaccharides studied may have therapeutic potential in inflammatory disorders [54].

\subsubsection{Rhamnan family and Arabinan family from Chlorophyceae}

In Clorophyta the major polysaccharides are polydisperse and highly branched sulphated heteropolysacccharides rich in rhamnose, galactose and arabinose sugars. The marine green algae represent an important biomass that is still little used compared to red and brown algae. And also compared to Rhodophyta, the reports on biological activities and anticoagulant activity of green algal polysaccharides are less abundant. Sulphated polysaccharides from two orders (Uvales and Bryopsidales) were mainly studied for their anticoagulant properties. Polysaccharides from Ulvales are glucuronoxylorhamnans rich in rhamnose, they are sulphated (22\% of ester sulphalte groups) and carboxylated (20\% of uronic acid sugars). The most frequent repeating sequence is D-glucuronosyl 1,4 linked $\alpha$-L-rhamnosyl-2sulphate 1,3 linked $\beta$-D-glucuronic acid with ramifications formed by 1,4 linked $\mathrm{D}$-xylose. In Bryopsidales, the sulphated polysaccharides are xylogalactoarabinans or xyloarabinogalactans, they are rich in arabinose or galactose respectively. The backbone consists of 1,4 linked L-arabinose blocks separated by D-galactose residues. All D-xylose residues and part of galactose residues are in terminal positions and they contain about $17 \%$ of ester sulphate groups.

In 1991, Maeda et al [55] compared the anticoagulant properties of different hot water extracts from Ulvales (Monostromataceae and Ulvaceae) and Bryopsidales (Codiaceae, Caulerpaceae and Bryopsidaceae). The yields of crude polysaccharides from dry algae were from 5 to $20 \%$ and the sulphate ester contents from crude polysaccharides were from 5 to 25\%. The most sulphated polysaccharides were found in Monostroma nitidum (Ulvales). After purification steps, the sulphated high rhamnose-containing polysaccharide $(65 \%$ of Lrhamnose, $6 \%$ of D-glucose, $5 \%$ of glucuronic acid and $23 \%$ of ester sulphate) was six-fold more anticoagulant than standard heparin measured by in vitro clotting assays.

The others studies reported the anticoagulant properties of sulphated polysaccharides isolated from different species of the genus Codium (Bryopsidales). Jurd described in 1995 [56] the anticoagulant properties of sulphated polysaccharides from Codium fragile ssp. atlanticum. After extraction and different purification steps (size exclusion and ion exchange chromatographies), different product were isolated and studied : a high molecular weight sulphated (18\%) proteoglycan and two lower molecular weight sulphated (7 and $10 \%$ of ester sulphate groups, respectively) polysaccharides. The highest anticoagulant activity using in vitro clotting assays (APTT, TT and PT) was found with the proteoglycan. In APTT, the concentrations required to double the control clotting time with proteoglycan, $7 \%$ sulphated 
polysaccharide and $10 \%$ sulphated polysaccharide were 4,30 and $250 \mu \mathrm{g} / \mathrm{mL}$, respectively. The proteoglycan isolated from Codium fragile ssp. Atlanticum inhibited thrombin and facto Xa through the catalysis of antithrombin III whereas the two polysaccharides inhibited only thrombin via heparin cofactor II catalysis. No direct activity on thrombin and factor Xa was demonstrated. The anticoagulant effect is correlated with the degree of sulphate but also the increase of the molecular weight.

In 1999, Siddhanta [57] isolated from the green marine alga Codium dwarkense Boergs. (Bryopsidales), two sulphated polysaccharides : one arabinan and one arabinogalactan. The very high molecular weight arabinan sulphate (estimated MW was $3 \times 10^{6}$ and containing only arabinose sugars and $40 \%$ of ester sulphate groups) exhibited stronger anticoagulant activity than the lower molecular weight arabinogalactan sulphate (estimated MW was $3 \times 10^{5}$ and containing arabinose and galactose residues and 32\% of ester sulphate groups). The anticoagulant activity is proportional to the arabinose and sulphate contents and inversely proportional to the protein and uronic acid contents, but also probably proportional to the molecular weight. The highly sulphated arabinan is only composed of $\alpha$-L-arabinofuranose. It prolongs APTT and TT, in APTT the same anticoagulant effect was obtained for the arabinan sulphate and heparin ( 140.3 units/mg) at 15 and $4 \mu \mathrm{g} / \mathrm{ml}$, respectively.

Recently, Ciancia et al [58] compared two species of the genus Codium (Bryopsidales), the crude extract isolated from Codium vermilara was more sulphated than the one from Codium fragile, 30 and $20 \%$, of ester sulphate groups, respectively. The two extracts were sulphated arabinogalactans, so the major sugars were galactose (62\% from C. fragile and $50 \%$ from $C$. vermilara) and arabinose $(23 \%$ from $C$. fragile and $45 \%$ from $C$. vermilara). The molecular weight of the arabinogalactan from $C$. vermilara was higher than the one from $C$. fragile (66 $\times 10^{3}$ and $11 \times 10^{3}$, respectively). The sulphated arabinogalactan from $C$. vermilara was the most active in clotting assays (in APTT, a same prolongation was observed at $20 \mu \mathrm{g} / \mathrm{ml}$ for the extract from $C$. vermilara and $100 \mu \mathrm{g} / \mathrm{ml}$ for the other one from $C$. fragile). As previously described above, the anticoagulant activity is proportional to the arabinose and sulphate contents but probably to the molecular weight.

\subsection{Heparin-like Entities from Marine Fungi}

The reports on sulphated polysaccharides from marine fungi are extremely rare. The main reason is may be because the native polysaccharides are not sulphated. In 2005, Chen et al studied the antiangiogenic activities of polysaccharides isolated from terrestrial medicinal fungi [59]. They are very high molecular weight neutral polysaccharides, the most active are rich in fucose, glucose and mannose; so Chen et al suggested that these monosaccharides may play a role in the inhibitory effect of these fungi on endothelial tube formation. In 2005, a polysaccharide YCP from a marine filamentous fungus Keissleriella sp. YS4108 was chemically sulphated. The YCP sulphate significantly prolonged clotting times (APTT, TT and PT) and the anticoagulant activity improved with the increasing degree of sulphation and decreased molecular weight [60].

\section{$4 \quad$ Concluding remarks and future directions}

Oligosaccharides showing heparin-like activities have been obtained from polysaccharides produced by marine bacteria. Relationship between the structure and the anticoagulant activities of marine polysaccharides and their derivatives remain to be established in order to fully control the production of therapeutic drugs. 
The demand for clean environmentally friendly processes is increasing significantly; biotechnology and in particular "white" biotechnology (which aims to avoid harmful substances by application of using enzymes as catalysts and utilization of renewable raw materials) may propose new processes for sustainable industry. Enzymes are ideal biocatalysts to assist in the synthesis of various compounds by offering catalysis with stereoand regio-selectivity, under mild conditions, in aqueous solutions. The use of an enzymatic step in processes involving sulphation may eliminate the need for solvents and multiple protection and de-protection steps increasing the final yield and lowering the duration. Sulfotransferases able to sulphate these EPS should be of high interest in the aim to produce bioactive derivatives. Marine bacteria producing sulphated polysaccharides would likely be a relevant source of new sulfotransferase enzymes to be active on these molecules. Although chemical synthesis was the major route to obtain structurally defined heparin oligosaccharides, the features of enzymatic methods to get oligosaccharides of biological relevance meet well the needs of better control of targeted modifications and of environmentally safer processing steps.

Furthermore, knowledge of the biosynthesis of EPS would facilitate the development of novel approaches, either by enzymes or by metabolic engineering, to synthesize heparinoids from marine bacterial EPS and to produce new molecules with high specificity for the biological target.

\section{References parts $1 \& 2$}

1. Sergeev VN, Gerasimenko LM, Zavarzin GA (2002) The proterozoic history and present state of cyanobacteria. Microbiol 71(6):623-637.

2. Rastogi RP, Sinha RP (2009) Biotechnological and industrial significance of cyanobacterial secondary metabolites. Biotechnol Adv 27(4):521-539.

3. Singh S, Kate BN, Banerjee UC (2005) Bioactive compounds from cyanobacteria and microalgae: an overview. Crit Rev Biotechnol 25(3):73-95.

4. Tan LT (2007) Bioactive natural products from marine cyanobacteria for drug discovery. Phytochem 68(7):954-979.

5. De Philippis R, Sili C, Paperi R et al (2001) Exopolysaccharide-producing cyanobacteria and their possible exploitation : a review. J Appl Phycol 13:293-299.

6. Parikh A, Madamwar D (2006) Partial characterization of extracellular polysaccharides from cyanobacteria. Bioresour Technol 97(15):1822-1827.

7. Lee J-B, Hayashi T, Hayashi K et al (2000) Structural Analysis of Calcium Spirulan (Ca-SP)-Derived Oligosaccharides Using Electrospray Ionization Mass Spectrometry. J Nat Prod 63(1):136-138.

8. Kaji T, Okabe M, Shimada S et al (2004) Sodium spirulan as a potent inhibitor of arterial smooth muscle cell proliferation in vitro. Life Sci 74(19):2431-2439.

9. Majdoub H, Mansour MB, Chaubet F et al (2009) Anticoagulant activity of a sulphated polysaccharide from the green alga Arthrospira platensis. Biochim Biophys Acta 1790(10):1377-1381.

10. Rechter S, Konig T, Auerochs S et al (2006) Antiviral activity of Arthrospira-derived spirulan-like substances. Antiviral Res 72(3):197-206.

11. Hayashi T, Hayashi K, Maeda M et al (1996) Calcium spirulan, an inhibitor of enveloped virus replication, from a blue-green alga Spirulina platensis. J Nat Prod 59(1):8387.

12. Hayakawa Y, Hayashi T, Hayashi K et al (1996) Heparin cofactor II-dependent antithrombin activity of calcium spirulan. Blood Coagul Fibrinolysis 7(5):554-560. 
13. Hayakawa Y, Hayashi T, Lee J-B et al (2000) Activation of heparin cofactor II by calcium spirulan. J Biol Chem 275(15):11379-11382.

14. Lee JB, Hou XL, Hayashi K et al (2007) Effect of partial desulphation and oversulphation of sodium spirulan on the potency of anti-herpetic activities. Carbohydr Polym 69(4):651-658.

15. Yamamoto C, Fujiwara Y, Kaji Tg (2006) The biological effects of depolymerized sodium spirulan and sulphated colominic acid on vascular cells are beneficial in preventing atherosclerosis. J Health Sci 52(3):205-210.

16. Zheng WF, Chen CF, Cheng QP et al (2006) Oral administration of exopolysaccharide from Aphanothece halophytica (Chroococcales) significantly inhibits influenza virus (H1N1)induced pneumonia in mice. Int Immunopharmacol 6(7):1093-1099.

17. Rehm BHA (2009) Microbial production of biopolymers and polymer precursors. Applications and perspectives. Caister Academic Press. 293p.

18. Sutherland IW (1998) Novel and established applications of microbial polysaccharides. Trends Biotechnol 16(1):41-46.

19. Kumar AS, Mody K (2009) Microbial exopolysaccharides : variety and potential applications. In : Microbial Production of Biopolymers and Polymer Precursors. Applications and Perspectives, Rehm BHA Ed. p229-253.

20. De Angelis PL (2002) Microbial glycosaminoglycan glycosyltransferases. Glycobiology 12(1):9R-16R.

21. Leali D, Belleri M, Urbinati C et al (2001) Fibroblast growth factor-2 antagonist activity and angiostatic capacity of sulphated Escherichia coli K5 polysaccharide derivatives. J Biol Chem 276(41):37900-37908.

22. Tharanathan RN, Kittur FS (2003) Chitin - The undisputed biomolecule of great potential. Crit Rev Food Sci Nutr 43(1):61-87.

23. Jayakumar R, Nwe N, Tokura S et al (2007) Sulphated chitin and chitosan as novel biomaterials. Int J Biol Macromol 40(3):175-181.

24. Nishimura S-I, Nishi N, Tokura S et al (1986) Inhibition of the hydrolytic activity of thrombin by chitin heparinoids. Carbohydr Res 156:286-292.

25. Whitman WB, Coleman DC, Wiebe WJ (1998) Prokaryotes: The unseen majority. Proc Natl Acad Sci USA 95(12):6578-6583.

26. Boeuf G, Kornprobst J-M (2009) Biodiversité et chimiodiversité marines. Biofutur 301:28-32.

27. Bourguet-Kondracki M-L, Banaigs B (2009) Des métabolites pas si secondaires. Biofutur 301:34-38.

28. Pace NR (1991) Origin of life-facing up to the physical setting. Cell 65(4):531-533.

29. Baross JA, Hoffman SE (1985) Submarine hydrothermal vents and associated gradient environments as sites for the origin and evolution of life. Orig Life Evol Biosph 15(4):327345 .

30. Miroshnichenko M, Bonch-Osmolovskaya E (2006) Recent developments in the thermophilic microbiology of deep-sea hydrothermal vents. Extremophiles 10(2):85-96.

31. Siezen RJ, Wilson G (2009) Genomics of deep-sea and sub-seafloor microbes. Microb Biotechnol 2(2):157-163.

32. Raguenes G, Pignet P, Gauthier G et al (1996) Description of a new polymer-secreting bacterium from a deep-sea hydrothermal vent, Alteromonas macleodii subsp. fijiensis, and preliminary characterization of the polymer. Appl Environ Microbiol 62(1):67-73.

33. Raguenes GH, Peres A, Ruimy R et al (1997) Alteromonas infernus sp. nov., a new polysaccharide-producing bacterium isolated from a deep-sea hydrothermal vent. J Appl Microbiol 82(4):422-430. 
34. Raguenes G, Christen R, Guezennec J et al (1997) Vibrio diabolicus sp. nov., a new polysaccharide-secreting organism isolated from a deep-sea hydrothermal vent polychaete annelid, Alvinella pompejana. Int J Syst Bacteriol 47(4):989-995.

35. Guo H, Yi W, Song JK et al (2008) Current understanding on biosynthesis of microbial polysaccharides. Curr Top Med Chem 8:141-151.

36. Mancuso Nichols CA, Garon S, Bowman JP et al (2004) Production of exopolysaccharides by Antarctic marine bacterial isolates. J Appl Microbiol 96:1057-1066.

37. Shanmugam M, Mody KH (2000) Heparinoid-active sulphated polysaccharides from marine algae as potential blood anticoagulant agents. Curr Sci 79(12):1672-1683.

38. Bramhachari PV, Dubey SK (2006) Isolation and characterization of exopolysaccharide produced by Vibrio harveyi strain VB23. Lett Appl Microbiol 43(5):571577.

39. Lerouge P, Roche P, Faucher C et al (1990) Symbiotic host-specificty of Rhizobium meliloti is determined by a sulphated and acylated glucosamine oligosaccharide signal. Nature 344:781-784.

40. Townsend GE, II, Forsberg LS, Keating DH (2006) Mesorhizobium loti produces nodPQ-dependent sulphated cell surface polysaccharides. J Bacteriol 188(24):8560-8572.

41. Vanbleu E, Choudhury BP, Carlson RW et al (2005) The nodPQ genes in Azospirillum brasilense $\mathrm{Sp} 7$ are involved in sulphation of lipopolysaccharides. Environ Microbiol 7(11):1769-1774.

42. Rivera-Marrero CA, Ritzenthaler JD, Newburn SA et al (2002) Molecular cloning and expression of a novel glycolipid sulfotransferase in Mycobacterium tuberculosis. Microbiology 148(3):783-792.

43. Matsuda M, Yamori T, Naitoh M et al (2003) Structural revision of sulphated polysaccharide B-1 isolated from a marine Pseudomonas species and its cytotoxic activity against human cancer cell lines. Mar Biotechnol 5:13-19.

44. Rougeaux H, Guezennec J, Carlson RW et al (1999) Structural determination of the exopolysaccharide of Pseudoalteromonas strain HYD721 isolated from a deep-sea hydrothermal vent. Carbohydr Res 315(3-4):273-285.

45. Roger O, Kervarec N, Ratiskol J et al (2004) Structural studies of the main exopolysaccharide produced by the deep-sea bacterium Alteromonas infernus. Carbohydr Res 339(14):2371-2380.

46. Mata JA, Béjar V, Bressollier P et al (2008) Characterization of exopolysaccharides produced by three moderately halophilic bacteria belonging to the family Alteromonadaceae. J Appl Microbiol 105(2):521-528.

47. Ivanova EP, Gorshkova RP, Mikhailov VV et al (1994) Capsular polysaccharides of marine-bacteria of the genus Alteromonas. Microbiol (Russ Acad Sci) 63(2):120-123.

48. Nazarenko EL, Gorshkova RP, Zubkov VA et al (1993) Structure of the repeating unit of the acidic polysaccharide from Alteromonas sp 4MC17. Bioorganicheskaya Khimiya 19(7):733-739.

49. Zubkov VA, Nazarenko EL, Gorshkova RP et al (1995) Structure of the capsular polysaccharide from Alteromonas sp. CMM 155. Carbohydr Res 275:147-154.

50. Perepelov AV, Shashkov AS, Torgov VI et al (2005) Structure of an acidic polysaccharide from the agar-decomposing marine bacterium Pseudoalteromonas atlantica strain IAM 14165 containing 5,7-diacetamido-3,5,7,9-tetradeoxy-1-glycero-1-manno-non-2ulosonic acid. Carbohydr Res 340(1):69-74.

51. Saravanan P, Jayachandran S (2008) Preliminary characterization of exopolysaccharides produced by a marine biofilm-forming bacterium Pseudoalteromonas ruthenica (SBT 033). Lett Appl Microbiol 46(1):1-6. 
52. Nazarenko EL, Komandrova NA, Gorshkova RP et al (2003) Structures of polysaccharides and oligosaccharides of some Gram-negative marine Proteobacteria. Carbohydr Res 338(23):2449-2457.

53. Bhaskar PV, Grossart H-P, Bhosle NB et al (2005) Production of macroaggregates from dissolved exopolymeric substances (EPS) of bacterial and diatom origin. FEMS Microbiol Ecol 53(2):255-264.

54. Rougeaux H, Kervarec N, Pichon R et al (1999) Structure of the exopolysaccharide of Vibrio diabolicus isolated from a deep-sea hydrothermal vent. Carbohydr Res 322(1-2):4045 .

55. Rougeaux H, Talaga P, Carlson RW et al (1998) Structural studies of an exopolysaccharide produced by Alteromonas macleodii subsp. fijiensis originating from a deep-sea hydrothermal vent. Carbohydr Res 312(1-2):53-59.

56. Rougeaux H, Pichon R, Kervarec N et al (1996) Novel bacterial exopolysaccharides from deep-sea hydrothermal vents. Carbohydr Polym 31(4):237-242.

57. Guezennec JG, Pignet P, Raguenes G et al (1994) Preliminary chemical characterization of unusual eubacterial exopolysaccharides of deep-sea origin. Carbohydr Polym 24(4):287-294.

58. Cambon-Bonavita MA, Raguenes G, Jean J et al (2002) A novel polymer produced by a bacterium isolated from a deep-sea hydrothermal vent polychaete annelid. J Appl Microbiol 93(2):310-315.

59. Rougeaux H, Kervarec N, Pichon R et al (1999) Structure of the exopolysaccharide of Vibrio diabolicus isolated from a deep-sea hydrothermal vent. Carbohydr Res 322:40-45.

60. Bramhachari PV, Kavi Kishor PB, Ramadevi R et al (2007) Isolation and characterization of mucous exopolysaccharide (EPS) produced by Vibrio furnissi strain VB0S3. J Microbiol Biotechnol 17(1):44-51.

61. Muralidharan J, Jayachandran S (2003) Physicochemical analyses of the exopolysaccharides produced by a marine biofouling bacterium, Vibrio alginolyticus. Process Biochem 38(6):841-847.

62. Guezennec J (2002) Deep-sea hydrothermal vents: a new source of innovative bacterial exopolysaccharides of biotechnological interest? $\mathrm{J}$ Ind Microbiol Biotechnol 29:204-208.

63. Zanchetta P, Lagarde N, Guezennec J (2003) A new bone-healing material: A hyaluronic acid-like bacterial exopolysaccharide. Calcif Tissue Int 72(1):74-79.

64. Colliec-Jouault S, Zanchetta P, Helley D et al (2004) Les polysaccharides microbiens d'origine marine et leur potentiel en thérapeutique humaine. Pathol Biol 52(3):127-130.

65. Colliec-Jouault S, Chevolot L, Helley D et al (2001) Characterization, chemical mdifications and in vitro anticoagulant properties of an exopolysaccharide produced by Alteromonas infernus. Biochim Biophys Acta 1528:141-151.

66. Okutani K (1984) Antitumor and immunostimulant activities of polysaccharide produced by a marine bacterium of the genus Vibrio. Bull Jap Soc Sci Fish 50(6):1035-1037.

67. Guezennec J, Pignet P, Lijour Y et al (1998) Sulphation and depolymerization of a bacterial exopolysaccharide of hydrothermal origin. Carbohydr Polym 37:19-24.

68. Nardella A, Chaubet F, Boisson-Vidal C et al (1996) Anticoagulant low molecular weight fucans produced by radical process and ion exchange chromatography of high molecular weight fucans extracted from the brown seaweed Ascophyllum nodosum. Carbohydr Res 289:201-208.

69. Zou W, Laferriere CA, Jennings HJ (1998) Oligosaccharide fragments of the type III group B streptococcal polysaccharide derived from S. pneumoniae type 14 capsular polysaccharide by a chemoenzymatic method. Carbohydr Res 309:297-301. 
70. Nishino $T$, Nagumo $T$ (1992) Anticoagulant and antithrombin activities of oversulphated fucans. Carbohydr Res 229(2):355-362.

71. Colliec-Jouault S, Roger O, Ratiskol J et al (2003) Bioactive bacterial exopolysaccharides: modification, characterization and preliminary results on biological activity. In : Marine Biotechnology : An Overview of Leading Field. Colliec S Ed. p141-147

\section{References part 3}

1. Kloareg B, Quatrano RS (1988) Structure of the Cell Walls of Marine Algae and Ecophysiological Functions of the Matrix Polysaccharides. Oceanography and Marine Biology : an Annual Review 26:259-315.

2. Shanmugam M, Mody KH (2000) Heparinoid-active sulphated polysaccharides from marine algae as potential blood anticoagulant agents. Current Science 79(12):1672-1683.

3. Pomin VH, Mourao PAS (2008) Structure, biology, evolution, and medical importance of sulfated fucans and galactans. Glycobiology 18(12):1016-1027.

4. Bourgougnon N, Lahaye M, Chermann J-C et al (1993) Composition and antiviral activities of a sulfated polysaccharide from schizymenia dubyi (rhodophyta, gigartinales). Bioorganic \& Medicinal Chemistry Letters 3(6):1141-1146.

5. Damonte E, Neyts J, Pujol CA et al (1994) Antiviral activity of a sulphated polysaccharide from the red seaweed nothogenia fastigiata. Biochemical Pharmacology 47(12):2187-2192.

6. Witvrouw M, De Clercq E (1997) Sulfated polysaccharides extracted from sea algae as potential antiviral drugs. General Pharmacology 29(4):497-511.

7. Schaeffer DJ, Krylov VS (2000) Anti-HIV activity of extracts and compounds from algae and cyanobacteria. Ecotoxicology and environmental safety 45(3):208-227.

8. Pereira MG, Benevides NMB, Melo MRS et al (2005) Structure and anticoagulant activity of a sulfated galactan from the red alga, Gelidium crinale. Is there a specific structural requirement for the anticoagulant action? Carbohydrate Research 340(12):2015-2023.

9. Hawkins WW, Leonard VG (1962) Antipeptic and antithrombic properties of carrageenin. J Lab Clin Med 60:641-8.

10. Anderson W, Duncan JGC (1965) Anticoagulant activity of carrageenan. 0022-3573 17(10):647-654.

11. Guven KC, Ozsoy Y, Ulutin ON (1991) Anticoagulant, Fibrinolytic and Antiaggregant Activity of Carrageenans and Alginic Acid. 0006-8055 34(5):429-432.

12. Carlucci MJ, Pujol CA, Ciancia M et al (1997) Antiherpetic and anticoagulant properties of carrageenans from the red seaweed Gigartina skottsbergii and their cyclized derivatives: correlation between structure and biological activity. Int $\mathrm{J}$ Biol Macromol 20(2):97-105.

13. Barabanova A, Shashkov A, Glazunov V et al (2008) Structure and properties of carrageenan-like polysaccharide from the red alga Tichocarpus crinitus (Gmel.) Rupr. (Rhodophyta, Tichocarpaceae). Journal of Applied Phycology 20(6):1013-1020.

14. Yamada T, Ogamo A, Saito T et al (1997) Preparation and anti-HIV activity of lowmolecular-weight carrageenans and their sulfated derivatives. Carbohydrate Polymers 32(1):51-55.

15. Opoku G, Qiu X, Doctor V (2006) Effect of oversulfation on the chemical and biological properties of kappa carrageenan. Carbohydrate Polymers 65(2):134-138.

16. Zuniga EA, Matsuhiro B, Mejias E (2006) Preparation of a low-molecular weight fraction by free radical depolymerization of the sulfated galactan from Schizymenia binderi (Gigartinales, Rhodophyta) and its anticoagulant activity. Carbohydrate Polymers 66(2):208215. 
17. Pushpamali WA, Nikapitiya C, De Zoysa M et al (2008) Isolation and purification of an anticoagulant from fermented red seaweed Lomentaria catenata. Carbohydrate Polymers 73(2):274-279.

18. Fonseca RJ, Oliveira SN, Melo FR et al (2008) Slight differences in sulfation of algal galactans account for differences in their anticoagulant and venous antithrombotic activities. Thromb Haemost 99(3):539-45.

19. Melo FR, Mourao PAS (2008) An algal sulfated galactan has an unusual dual effect on venous thrombosis due to activation of factor XII and inhibition of the coagulation proteases. Thromb Haemost 99(3):531-538.

20. Chevolot L, Mulloy B, Ratiskol J et al (2001) A disaccharide repeat unit is the major structure in fucoidans from two species of brown algae. Carbohydrate Research 330(4):52935.

21. Berteau O, Mulloy B (2003) Sulfated fucans, fresh perspectives: structures, functions, biological properties of sulfated fucans and overview of enzymes active towards this class of polysaccharide. Glycobiology.

22. Springer GF, Wurzel HA, Mc Neal GM et al (1957) Isolation of Anticoagulant Fractions from Crude Fucoidin. Proceedings of the Society for Experimental Biology and Medicine 94:404-408.

23. Bernardi G, Springer GF (1962) Properties of Highly Purified Fucan. Journal of Biological Chemistry 237(1):75-80.

24. Deaconsmith RA, Leepotter JP, Rogers DJ (1985) Anticoagulant Activity in Extracts of British Marine-Algae. 0006-8055 28(8):333-338.

25. Nishino T, Yokoyama G, Dobashi K et al (1989) Isolation, purification, and characterization of fucose-containing sulfated polysaccharides from the brown seaweed Ecklonia kurome and their blood-anticoagulant activities. Carbohydrate Research 186(1):119-29.

26. Grauffel V, Kloareg B, Mabeau S et al (1989) New natural polysaccharides with potent antithrombic activity: fucans from brown algae. Biomaterials 10(6):363-8.

27. Church FC, Meade JB, Treanor RE et al (1989) Antithrombin activity of fucoidan. The interaction of fucoidan with heparin cofactor II, antithrombin III, and thrombin. Journal of Biological Chemistry 264(6):3618-23.

28. Colliec S, Fischer AM, Taponbretaudiere J et al (1991) Anticoagulant Properties of a Fucoidan Fraction. Thrombosis Research 64(2):143-154.

29. Nishino T, Aizu Y, Nagumo T (1991) The influence of sulfate content and molecular weight of a fucan sulfate from the brown seaweed Ecklonia kurome on its antithrombin activity. Thrombosis Research 64(6):723-31.

30. Soeda S, Sakaguchi S, Shimeno H et al (1992) Fibrinolytic and anticoagulant activities of highly sulfated fucoidan. Biochemical Pharmacology 43(8):1853-1858.

31. Soeda S, Ohmagari Y, Shimeno H et al (1993) Preparation of oversulfated fucoidan fragments and evaluation of their antithrombotic activities. Thrombosis Research 72(3):24756.

32. Mauray S, Sternberg C, Theveniaux J et al (1995) Venous antithrombotic and anticoagulant activities of a fucoidan fraction. J. Thromb. Haemost. 74:1280-1285.

33. Millet J, Jouault SC, Mauray S et al (1999) Antithrombotic and anticoagulant activities of a low molecular weight fucoidan by the subcutaneous route. J. Thromb. Haemost. 81(3):391-5.

34. Colliec-Jouault S, Millet J, Helley D et al (2003) Effect of low-molecular-weight fucoidan on experimental arterial thrombosis in the rabbit and rat. J. Thromb. Haemost. 1(5):1114-5. 
35. Durand E, Helley D, Zen AAH et al (2008) Effect of Low Molecular Weight Fucoidan and Low Molecular Weight Heparin in a Rabbit Model of Arterial Thrombosis. J Vasc Res 45(6):529-537.

36. Giraux JL, Tapon Bretaudiere J, Matou S et al (1998) Fucoidan, as heparin, induces tissue factor pathway inhibitor release from cultured human endothelial cells. J. Thromb. Haemost. 80(4):692-695.

37. Thorlacius H, Vollmar B, Seyfert UT et al (2000) The polysaccharide fucoidan inhibits microvascular thrombus formation independently from P- and L-selectin function in vivo. European Journal of Clinical Investigation 30(9):804-10.

38. Glabe CG, Yednock T, Rosen SD (1983) Reversible Disruption of Cultured Endothelial Monolayers by Sulfated Fucans. Journal of Cell Science 61(May):475-490.

39. Giraux JL, Matou S, Bros A et al (1998) Modulation of human endothelial cell proliferation and migration by fucoidan and heparin. European Journal of Cell Biology 77:352-359.

40. Matou S, Helley D, Chabut D et al (2002) Effect of fucoidan on fibroblast growth factor-2-induced angiogenesis in vitro. Thrombosis Research 106(4-5):213.

41. Chabut D, Fischer AM, Colliec-Jouault S et al (2003) Low molecular weight fucoidan and heparin enhance the basic fibroblast growth factor-induced tube formation of endothelial cells through heparan sulfate-dependent alpha 6 overexpression. Molecular Pharmacology 64(3):696-702.

42. Chabut D, Fischer AM, Helley D et al (2004) Low molecular weight fucoidan promotes FGF-2-induced vascular tube formation by human endothelial cells, with decreased PAI-1 release and ICAM-1 downregulation. Thrombosis Research 113(1):93-95.

43. Logeart D, Prigent-Richard S, Boisson-Vidal C et al (1997) Fucans, sulfated polysaccharides extracted from brown seaweeds, inhibit vascular smooth muscle cell proliferation. II. Degradation and molecular weight effect. European Journal of Cell Biology 74(4):385-90.

44. Deux JF, Meddahi-Pelle A, Le Blanche AF et al (2002) Low molecular weight fucoidan prevents neointimal hyperplasia in rabbit iliac artery in-stent restenosis model. Arteriosclerosis, Thrombosis, and Vascular Biology 22(10):1604-9.

45. Luyt CE, Meddahi-Pelle A, Ho-Tin-Noe B et al (2003) Low-Molecular-Weight Fucoidan Promotes Therapeutic Revascularization in a Rat Model of Critical Hindlimb Ischemia. Journal of Pharmacology and Experimental Therapeutics 305(1):24-30.

46. Chauvet P, Bienvenu JG, Theoret JF et al (1999) Inhibition of platelet-neutrophil interactions by fucoidan reduces adhesion and vasoconstriction after acute arterial injury by angioplasty in pigs. Journal of Cardiovascular Pharmacology 34(4):597-603.

47. Alkhatib B, Freguin-Bouilland C, Lallemand F et al (2006) Low molecular weight fucan prevents transplant coronaropathy in rat cardiac allograft model. 0966-3274 16(1):1419.

48. Sweeney EA, Lortat-Jacob H, Priestley GV et al (2002) Sulfated polysaccharides increase plasma levels of SDF-1 in monkeys and mice: involvement in mobilization of stem/progenitor cells. Blood 99(1):44-51.

49. Zemani F, Benisvy D, Galy-Fauroux I et al (2005) Low-molecular-weight fucoidan enhances the proangiogenic phenotype of endothelial progenitor cells. Biochemical Pharmacology 70(8):1167-1175.

50. Boisson-Vidal C, Zemani F, Caligiuri G et al (2007) Neoangiogenesis induced by progenitor endothelial cells: effect of fucoidan from marine algae. Cardiovasc Hematol Agents Med Chem 5(1):67-77. 
51. Tissot B, Montdargent B, Chevolot L et al (2003) Interaction of fucoidan with the proteins of the complement classical pathway. Biochimica et Biophysica Acta (BBA) Proteins \& Proteomics 1651(1-2):5-16.

52. Angstwurm K, Weber JR, Segert A et al (1995) Fucoidin, a Polysaccharide Inhibiting Leukocyte Rolling, Attenuates Inflammatory Responses in Experimental Pneumococcal Meningitis in Rats. 0304-3940 191(1-2):1-4.

53. Cumashi A, Ushakova NA, Preobrazhenskaya ME et al (2007) A comparative study of the anti-inflammatory, anticoagulant, antiangiogenic, and antiadhesive activities of nine different fucoidans from brown seaweeds. Glycobiology 17(5):541-552.

54. Medeiros VP, Queiroz KCS, Cardoso ML et al (2008) Sulfated galactofucan from Lobophora variegata: Anticoagulant and anti-inflammatory properties. Biochemistry-Moscow 73(9):1018-1024.

55. Maeda M, Uehara T, Harada $\mathrm{N}$ et al (1991) Heparinoid-active sulphated polysaccharides fromMonostroma nitidum and their distribution in the chlorophyta. Phytochemistry 30(11):3611-3614.

56. Jurd KM, Rogers DJ, Blunden G et al (1995) Anticoagulant properties of sulphated polysaccharides and a proteoglycan from Codium fragile ssp. atlanticum. Journal of Applied Phycology 7:339-345.

57. Siddhanta AK, Shanmugam M, Mody KH et al (1999) Sulphated polysaccharides of Codium dwarkense Boergs. from the west coast of India: chemical composition and blood anticoagulant activity. International Journal of Biological Macromolecules 26(2-3):151-4.

58. Ciancia M, Quintana I, Vizcarguenaga MI et al (2007) Polysaccharides from the green seaweeds Codium fragile and $\mathrm{C}$ vermilara with controversial effects on hemostasis. International Journal of Biological Macromolecules 41(5):641-649.

59. Chen SC, Lu MK, Cheng JJ et al (2005) Antiangiogenic activities of polysaccharides isolated from medicinal fungi. 0378-1097 249(2):247-254.

60. Han F, Yao W, Yang X et al (2005) Experimental study on anticoagulant and antiplatelet aggregation activity of a chemically sulfated marine polysaccharide YCP. International Journal of Biological Macromolecules 36(4):201-207. 